\title{
Assessing landscape features and ecosystem services of marine protected areas through photographs on social media: comparison of two archipelagos in Spain
}

\author{
D. Alieva ${ }^{1}$ - D. Holgado ${ }^{2}$ S. de Juan ${ }^{3} \cdot$ A. Ruiz-Frau ${ }^{4} \cdot$ S. Villasante ${ }^{5} \cdot$ I. Maya-Jariego $^{2}$ (iD
}

Received: 7 June 2021 / Accepted: 16 September 2021 / Published online: 30 September 2021

(C) The Author(s) 2021

\begin{abstract}
Marine protected areas provide cultural services including the aesthetic appreciation of the landscape and the performance of recreational activities. In this study, we use the photographs shared by users in a digital repository to describe the distinctive characteristics of two terrestrial-maritime natural parks in Spain. In total, 1041 photos and 2342 tags generated by 76 users were analyzed. The results show the greatest salience of the landscape values, followed by historical monuments and the sighting of fauna and flora. The methodology based on the extraction of digital data from Flickr facilitates the efficient comparison of a Mediterranean archipelago (Cabrera Island) with an Atlantic archipelago (Cíes Islands). However, some important limitations were also detected in the descriptive capacity of this method, in comparison with the content analysis by external observers. But, overall, the evaluation of the subjective experience of visitors to natural areas can be very useful for tourism management of the marine environment.
\end{abstract}

Keywords Cultural ecosystem services $\cdot$ Landscape $\cdot$ Marine protected areas $\cdot$ Social media $\cdot$ User-generated content

\section{Introduction}

Marine protected areas are governance tools that have proven effective for biodiversity conservation, preserving over-exploited species, and protecting the integrity of marine ecosystems (Jentoft et al., 2007). Management efforts often focus primarily on reducing overfishing and, in addition, offer coastal communities alternatives for socioeconomic development, generally through coastal tourism (Fonseca et al., 2014). In both cases, the

\section{Maya-Jariego}

isidromj@us.es

1 Management Development Institute of Singapore in Tashkent, Tashkent, Uzbekistan

2 Universidad de Sevilla, Sevilla, Spain

3 CSIC, Institut de Ciències del Mar, Barcelona, Spain

4 CSIC, Instituto Mediterraneo de Estudios Avanzados, Esporles, Spain

5 Universidad de Santiago de Compostela, Santiago de Compostela, Spain 
conservation outcomes are highly variable, depending on key factors such as the size of marine protected areas, time-span or the governance in place (Ban et al., 2017; Di Franco et al., 2016; Sciberras et al., 2015). To minimize overfishing, the most effective marine protected areas are those that do not allow fish to be caught (i.e., no-take zones), have been operating for more than 10 years, have a consolidated and effective monitoring system, are large enough, and are isolated by deep water or sand (Di Franco et al., 2016; Edgar et al., 2014). On the other hand, the tourist attraction of natural areas may depend on the climate, the number of species, the variety of habitats, and the existence of cultural infrastructures (Wood et al., 2013).

Previous studies have shown that marine protected areas influence the maintenance of ecosystem integrity and the long-term delivery of ecosystem services. They can improve food security, contribute to the generation of jobs linked to tourism, and facilitate the continuity of some traditional occupations (Leenhardt et al., 2015). The conservation of unique habitats is one of the resources with tourist potential to which they normally contribute. Both the landscape characteristics and the cultural services derived from the ecosystem are the main driver of fauna composition (Hogg et al., 2018) and, consequently, of people's perception of the natural environment (Petrosillo et al., 2007), and their relationship with nature (Willis, 2015).

Recently, data shared on the internet have started to be used as a way to assess ecosystem services and analyze the perception of the citizens in natural areas. In general, data shared on social media allow for the assessment of tourists' preferences for ecosystem attributes in protected natural areas (Hausmann et al., 2018). More specifically, digital photographs can be used to examine the characteristics of the landscape, and indirectly inform about the cultural services provided by iconic ecosystems (de Juan et al., 2021; Retka et al., 2019). Furthermore, the geolocation of the images published online is an efficient indicator of the volume of visits and their preferences for different recreational places (Wood et al., 2013).

However, as it is a methodological approach still under development, most of the studies carried out so far are descriptive in nature and focus on calibrating the procedures for data extraction and evaluation of the information obtained (Oteros-Rozas et al., 2018; Retka et al., 2019; Ruiz-Frau et al., 2020). On the one hand, there are ecosystem services that are more susceptible to graphic representation than others. The appreciation of fauna, for example, may be more objective than artistic values, which may depend in part on the interpretation of the observer. On the other hand, the information shared by users is not systematic, nor is it necessarily representative, as it can be affected by generational, nationality, and case study location biases, and can sometimes be simply inaccurate. Consequently, the inductive management of large digital databases has enormous descriptive potential, as long as data caveats are acknowledged and adequately managed. For this reason, it is useful to have external validation elements, together with prior knowledge of the areas under analysis. Among other strategies, methodological triangulation, content analysis, and network analysis are highly recommended (Toivonen et al., 2019). That is the approach we follow in this work.

In this study, we rely on digital content generated by users to analyze the distinctive characteristics of marine protected areas. Particularly, we focused on two protected islands in Spain, namely Cabrera (Spanish NW Mediterranean) and the Cíes Islands (Spanish NE Atlantic). We used a selection of photographs shared on Flickr with tags that referred to these areas. This approach allows us to test the suitability of the methodological approach when characterizing two different natural contexts. In addition, in the case of Flickr, we can combine the visual reproduction of the natural environment (i.e., posted photographs) 
with the tags assigned by the users to each photograph. The objectives of the research were: (a) to describe the characteristics of the landscape of two marine protected areas through the photographs shared in an online image repository; (b) to evaluate the cultural services provided by marine ecosystems in the two archipelagos under study, and (c) to analyze the usefulness and limitations of a methodological approach based on tag network extraction and image content analysis.

To achieve these objectives, we inductively describe the characteristics of the seascape through the analysis of networks of the tags shared by the users. As an element of contrast, we resort to photo content analyses carried out by external observers. This comparison allows us to assess the contribution, efficiency, and limitations of using social media to describe the perception of ecosystems by the population. With this study, we compare two marine protected areas in Spain that have little official available information on their visitors' profiles and preferences. Although the methodological approach has already been put into practice previously (Ruiz-Frau et al., 2020), and has proven to be cost-effective (de Juan et al., 2021), here we verify its usefulness to describe visitors' perception, as well as their recognition of the ecological values of the visited natural areas. We also generate information that can be useful for the policy makers to locally manage the studied areas.

\section{Method}

\subsection{Study area}

The study was carried out in two protected natural areas in Spain: the Island of Cabrera and the Cíes Islands, located, respectively, in the NW Mediterranean and in the NE Atlantic.

The Cabrera archipelago is a protected natural area of the Balearic Islands. It has a magnificently well-preserved coastal landscape and is home to large colonies of seabirds, among other natural values. In 1991 it was declared a National Maritime-Terrestrial Park and is part of the Natura 2000 network, and it comprises more than 20 endemic species from the Balearic environment. Among other conservation actions, a monitoring program is being carried out on the native seagrass Posidonia oceanica. Posidonia is included in Annex 1 of the Habitats Directive (92/43/CEE) as a habitat of conservation priority. The population in the Balearic Islands is highly dependent on coastal ecosystems, which has historically driven coastal ecosystem degradation, exacerbated by a more recent explosion of tourists' affluence in demand for recreational space. The historical use of the coast is the main driver of current ecosystem status, with Posidonia beds impacted by multiple uses including anchoring, pollution, recreational, and commercial fisheries.

The archipelago of the Cíes Islands is located in the Rías Baixas in Galicia. It is characterized by a landscape of cliffs, with a great wealth of seabed habitats. It is part of the Maritime-Terrestrial National Park of the Atlantic Islands of Galicia, established in 2002. Among other natural values, kelp forests, the dune systems, and the Atlantic coastal scrub stand out. Conservation actions focus on the management of waste, anchoring boats, and fishing. The Cíes Islands are included as a Site of Community Importance (SCI) and Special Protection Area (SPA) for birds in the European Nature Network. The waters around the Cíes Islands were traditionally used as a fishing ground both by small-scale and coastal purse seiners, although a part of such a zone now belongs to the natural park, where fishing is not allowed (Cambiè et al., 2012). 


\subsection{Data collection and processing}

To select the social media platform to be used in the study, we reviewed the photographs associated to Galapagos Islands, ${ }^{1}$ Cabrera Archipelago, and the Cíes Islands on Instagram and Flickr. In all three cases, it was found that the photos shared by users on Instagram tended to focus on personal travel experiences, with a high prevalence of selfies and an overall subjective representation of the relationship with the environment. On the other hand, on Flickr, landscape photographs were more abundant, which facilitates the evaluation of the ecosystem uses and services of the environment. In the latter, the geolocation of images is more frequent and descriptive tags associated with the photographs are generally used. In addition, it has also been previously used for research purposes, with good results (Oteros-Rozas et al., 2018).

Consequently, we opted for Flickr to generate the database for further analysis. For this, systematic explorations were carried out, with the criteria of search by tags, using the Flickr Application Programming Interface (API) and covering thirteen months (from January 1, 2017 to January 31, 2018). With the tags "isla_de_cabrera," in the first place, and "mallorca + cabrera," in second place, 1311 entries were obtained. After removing 7 duplicates, we obtained 154 unique photos with 827 tags. Regarding the Cíes Islands, the terms "islands_cies" and "cies" were used to retrieve 12,765 photographs. After eliminating duplicates, the list was reduced to 907 unique photos.

The second step consisted of the manual processing of the photographs. On the one hand, duplicate tags were removed, leaving only one variant of each word. For example, for a photograph tagged as "isola, isla, insel, island, islands," only the term "island" was retained. On the other hand, we discarded photographs not related to the subject under study. For example, we eliminated photographs representing graffiti and demonstrations that referred to the Centers for the Internment of Foreigners (CIES, according to its Spanish acronym), associated to the tag "cies." In the case of the Cíes Islands, this meant the elimination of 20 entries to keep a total of 887 photos. In this phase, we also carried out the thematic grouping of tags that appeared infrequently. For example, "seagulls," "cormorants," and "gannets" were re-categorized as "birds."

Next, a semantic network of tags was generated with the use of the AutoMap software (Carley et al., 2012), which was analyzed with ORA (Altman et al., 2017). The resulting graph is made up of 482 tags and 1522 connections in the case of Cabrera, compared to 1860 tags and 7130 connections in the case of the Cíes Islands. The entire process is summarized in Table 1.

To evaluate tag networks, we used individual centrality measures. For each tag, Degree, Betweenness, and Eigenvector measures were calculated. Degree centrality consists of the count of the total number of connections linked to a node (in this case, to each label). Betweenness centrality of each tag reflects the number of shortest paths between pairs of nodes in the network that pass through that tag. It serves to identify those nodes that act as bridges, connecting different parts of the network. Eigenvector centrality calculates the centrality of a node based on the centrality of those to which it is connected.

Two descriptors for each complete network were also calculated: Density and Average distance. Density is the proportion of existing relationships in the network out of all possible relationships. In weighted networks, it is calculated as the sum of the weights of the

\footnotetext{
1 The Galapagos Islands were analyzed for exploratory purposes in a phase prior to the design of the research, before focusing the study objectives on the two protected areas in Spain.
} 


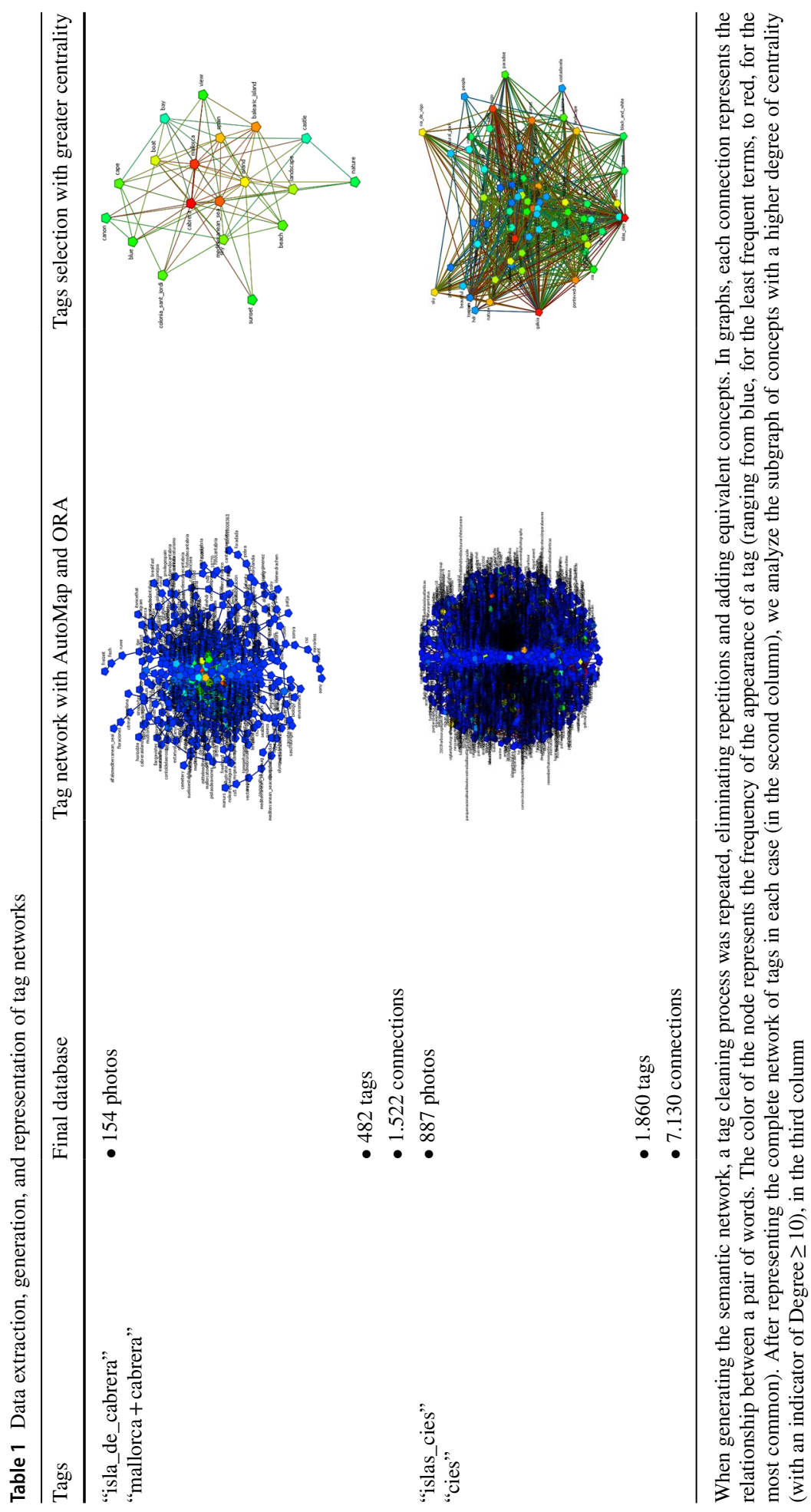


relationships in the graph, divided by the number of possible relationships. Finally, Average distance is the average shortest path on a graph, corresponding to the sum of all the shortest paths between pairs of nodes divided by the total number of pairs of nodes. This is a selection of some of the most common measures to describe centrality and cohesion in networks (Maya-Jariego et al., 2016).

\subsection{Content analysis}

Based on previous studies, we designed an observation guide to evaluate the content of the images (Hausmann et al., 2018), the photographic motifs, and the ecosystem services (Ruiz-Frau et al., 2020) represented in them. For this, we selected two random subsamples of 60 photographs from each study area (Cabrera and the Cíes Islands).

Firstly, images were coded indicating the presence or absence of the following categories: landscape, biodiversity, posing, human activity, accommodation, and food (Hausmann et al., 2018). A photograph was considered to represent the landscape when it encompassed an area of land, sea, or coast, with a visible horizon. The category "biodiversity" referred to images in which animals, trees or plants were the central subjects of the photo. "Posing" encompassed those photographs with people looking at the camera (either in the format of selfies or photographic portraits), while the "human activity" category represented people undertaking recreational activities or similar actions. Appearances of tourist infrastructures were registered as "accommodation". Finally, photographs showing food or drink were identified as "food". Each image could fall under several categories.

Secondly, based on an initial qualitative scan, some of the most frequent photographic motifs were accounted for. Specifically, in each photograph the presence of (1) "sea and rock landscapes," (2) "people on the beach," (3) "animals," (4) "lighthouse or castle," (5) "sunsets," and (6) "boats" was recorded. Similarly, one image could fall under several categories.

Finally, the degree of perceived association of the image with each of the following ecosystem services was scored from 1 to 5 by two observers: cultural or artistic expression, living cultural heritage, historical monuments and infrastructures, landscape appreciation, nature appreciation, natural monuments, ceremonies or religious activities, research or education, social activities, recreational activities, and "others" (Retka et al., 2019; RuizFrau et al., 2020). The scale used ranged from "not present" $(=1)$ to "very present" $(=5)$ in each photograph. The two observers were doctors in psychology, with experience in the behavioral assessment of interaction settings. To evaluate the consistency between observers, the intraclass correlation index (ICC) was calculated with a mixed model of two factors in the SPSS 26 (IBM Corp, 2019).

The first two classifications focused on the recognition of the presence (or absence) of easily recognizable motifs in the photograph (e.g., animals, boats or people on the beach). However, the valuation of cultural ecosystem services depended on the interpretation of observers and may be subject to greater variability. As an illustration, in Fig. 1 we show three photographs that vary in the relative presence of two ecosystem services: landscape appreciation and recreational activities. ${ }^{2}$ To establish differences between the two case studies, systematic mean comparisons were made with Student's t test.

\footnotetext{
2 To show examples with a Creative Commons license, both in Fig. 1 and in Fig. 3 below, we have used photographs outside the period analyzed.
} 

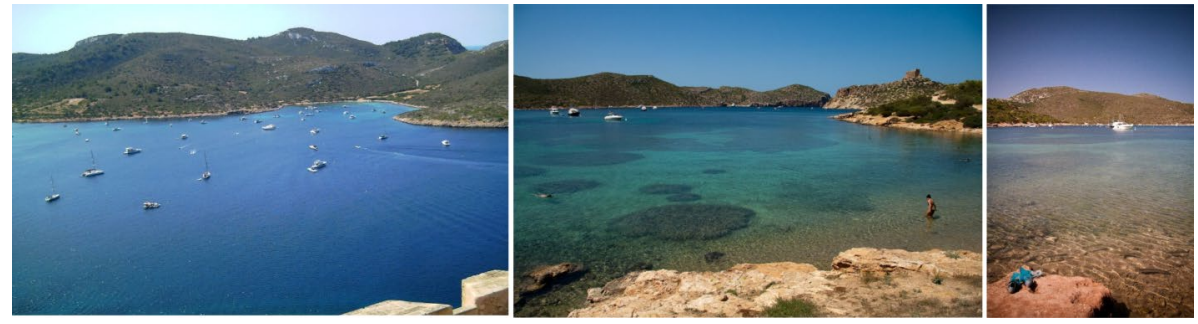

Fig. 1 The relative presence of ecosystem services in photographs. The three photographs combine the appreciation of the landscape with the representation of recreational activities. The photo on the left of the panel shows a coastal landscape where recreational boats anchor. In the center, the photo focuses attention on snorkeling or bathing activities, with a coastal landscape in the background. On the right, the photo shows some diving fins in the foreground, with fish that can be seen during the dive. From the left to the right, photos show: "Anchoring in Cabrera Island" by Germán Prados (CC BY 2.0), https://www.flickr.com/ photos/hermanprados/9387057006/; "Cas Pagés” by Iñaki Pérez Albéniz (CC BY 2.0), https://www.flickr. com/photos/atreyusan/4911180636/; and "Diving” by Iñaki Pérez (CC BY 2.0), https://www.flickr.com/ photos/atreyusan/7129597057/

\section{Results}

\subsection{Descriptive analysis of tags}

Table 2 summarizes the most frequent tags used for the description of the photographs. Geographical references are the most common tags used both in the case of Cabrera Island (e.g., Mallorca, Mediterranean Sea, Balearic Islands, Spain) and the Cíes Islands (e.g., Galicia, Vigo, Pontevedra, Spain). For the rest, both archipelagos broadly coincide in the type of content present in the images.

The Cíes Islands have a greater volume of tags and a denser interconnection network. However, in both cases, references to recreational activities, such as boat trips, summer vacations or sun and beach tourism, predominate in our findings. The appreciation of the landscape is also frequent, but to a lesser extent. Flickr users resort to a minimalist description of the views, with a combination of "sea" and "sky," with "rocks" and "cliffs" as little contrasting elements. Another recurring theme is the "sunsets," and in a complementary way, "nature," "wildlife" or the nature of a protected area stand out as values of the environment.

The representation only varies slightly in identifying places of interest. In Cabrera Island, the lighthouse, the castle, and the blue cave stand out, while in the Cíes Islands the attention is focused on the lighthouse. Occasionally, photos of the ports from which the boat visit begins were also classified by users with tags referring to Cabrera or Cíes: respectively, the Colonia de Sant Jordi in Mallorca, and the ports of Vigo, Cangas, Baiona, and Pobra do Caramiñal in the Rías Baixas.

\subsection{Tag networks}

To examine the properties of the tag network, we removed those tags referring to geographic locations, as they made it infeasible to appreciate the details of the network. Basic measures of centrality were computed, namely Degree, Betweenness, and 
Table 2 Most frequent tags in the description of the photographs

\begin{tabular}{|c|c|c|c|c|c|}
\hline \multicolumn{3}{|l|}{ Cabrera Island } & \multicolumn{3}{|l|}{ Cíes Islands } \\
\hline Tag & $N$ & $\%$ & Tag & $N$ & $\%$ \\
\hline Cabrera & 153 & 99.35 & islas_cies & 887 & 100.00 \\
\hline Mallorca & 150 & 97.40 & Galicia & 478 & 53.89 \\
\hline mediterranean_sea & 61 & 39.61 & Sea & 290 & 32.69 \\
\hline balearic_island & 49 & 31.82 & Vigo & 282 & 31.79 \\
\hline Spain & 42 & 27.27 & Spain & 265 & 29.88 \\
\hline Island & 34 & 22.08 & Beach & 186 & 20.97 \\
\hline Boat & 29 & 18.83 & Sunset & 150 & 16.91 \\
\hline Landscape & 16 & 10.39 & Pontevedra & 114 & 12.85 \\
\hline Sky & 13 & 8.44 & Wildlife & 86 & 9.70 \\
\hline Beach & 12 & 7.79 & Nature & 81 & 9.13 \\
\hline Cape & 12 & 7.79 & Landscape & 76 & 8.57 \\
\hline colonia_sant_jordi & 12 & 7.79 & Sky & 67 & 7.55 \\
\hline Blue & 11 & 7.14 & ria_de_vigo & 60 & 6.76 \\
\hline View & 11 & 7.14 & Boat & 58 & 6.54 \\
\hline Palma & 10 & 6.49 & Blue & 56 & 6.31 \\
\hline Sunset & 10 & 6.49 & Lighthouse & 56 & 6.31 \\
\hline blue_cave & 9 & 5.84 & rias_baixas & 56 & 6.31 \\
\hline Canon & 9 & 5.84 & Summer & 55 & 6.20 \\
\hline Nature & 9 & 5.84 & Clouds & 51 & 5.75 \\
\hline national_park & 8 & 5.19 & Rocks & 51 & 5.75 \\
\hline Bay & 7 & 4.55 & Sun & 49 & 5.52 \\
\hline Castle & 7 & 4.55 & Water & 46 & 5.19 \\
\hline Clouds & 7 & 4.55 & View & 41 & 4.62 \\
\hline Lighthouse & 7 & 4.55 & & & \\
\hline Formentera & 6 & 3.90 & & & \\
\hline Rocks & 6 & 3.90 & & & \\
\hline Archipelago & 5 & 3.25 & & & \\
\hline Coast & 5 & 3.25 & & & \\
\hline Ibiza & 5 & 3.25 & & & \\
\hline Nikon & 5 & 3.25 & & & \\
\hline Sun & 5 & 3.25 & & & \\
\hline Vacation & 5 & 3.25 & & & \\
\hline
\end{tabular}

Eigenvector. This last indicator allows evaluating the relative importance of the tag regardless of the frequency of appearance of each tag (Ruiz-Frau et al., 2020). The results are summarized in Table 3.

The Cabrera network has a density of 0.162 and an average distance of 2.169. The Cíes Islands network has a density of 0.725 and an average distance of 1.275. A higher density and a lower average distance show more complex description of the photos, to the extent that users have assigned them a greater number of tags connected to each other. In the two archipelagos, "beach," "sky," and "landscape" are counted in the first quartile of the best-connected tags. On the other hand, the terms with the greatest intermediation capacity are "island" in the case of Cabrera, and "beach" in the Cíes. As a result, we find that, in addition to the importance of appreciating the landscape, 
Table 3 Centrality measures of tags in co-occurrence networks

\begin{tabular}{|c|c|c|c|c|c|c|c|}
\hline \multicolumn{4}{|l|}{ Cabrera Island } & \multicolumn{4}{|l|}{ Cíes Islands } \\
\hline Tag & $D$ & $B$ & $E$ & Tag & $D$ & $B$ & $E$ \\
\hline Island & 52 & 132.65 & 1 & Sea & 209 & 3.425 & 1 \\
\hline Boat & 20 & 4.3 & 0.67 & Beach & 119 & 13.925 & 0.724 \\
\hline Landscape & 14 & 1.7 & 0.505 & Sky & 119 & 1.625 & 0.672 \\
\hline Beach & 10 & 8.083 & 0.358 & Landscape & 89 & 1.949 & 0.586 \\
\hline Sky & 12 & 16.583 & 0.299 & Blue & 81 & 1.368 & 0.501 \\
\hline Bay & 8 & 5.483 & 0.293 & Water & 80 & 1.625 & 0.485 \\
\hline View & 6 & 0 & 0.250 & Sunset & 67 & 1.402 & 0.382 \\
\hline Lighthouse & 10 & 4.5 & 0.221 & Nature & 48 & 1.658 & 0.288 \\
\hline Nature & 12 & 14.917 & 0.217 & Clouds & 45 & 0.302 & 0.283 \\
\hline National park & 4 & 0 & 0.213 & Rocks & 42 & 1.248 & 0.249 \\
\hline Castle & 12 & 21.7 & 0.211 & Lighthouse & 33 & 0.091 & 0.199 \\
\hline Blue & 8 & 12.95 & 0.192 & Sun & 30 & 1.213 & 0.176 \\
\hline Sunset & 10 & 29.45 & 0.140 & Boat & 23 & 0.667 & 0.153 \\
\hline Archipelago & 4 & 0 & 0.130 & Summer & 10 & 0 & 0.064 \\
\hline Nikon & 4 & 0 & 0.130 & View & 7 & 2.5 & 0.031 \\
\hline Rocks & 6 & 4.617 & 0.123 & Wildlife & 2 & 0 & 0.007 \\
\hline Cape & 8 & 1.867 & 0.078 & & & & \\
\hline Vacation & 4 & 0.5 & 0.061 & & & & \\
\hline Canon & 6 & 7.25 & 0.055 & & & & \\
\hline Sun & 6 & 0 & 0.032 & & & & \\
\hline Clouds & 6 & 3.45 & 0.024 & & & & \\
\hline Coast & 2 & 0 & 0.023 & & & & \\
\hline Blue cave & 0 & 0 & 0 & & & & \\
\hline
\end{tabular}

The calculated measures of centrality correspond to Degree (D), Betweenness (B), and Eigenvector (E). Degree centrality reports the number of ties that a tag has with the others. The Betweenness centrality reports the number of geodetic paths that pass through said tag. The Eigenvector centrality of a tag is high insofar as it is connected with other tags with high centrality. In the table the tags are ordered according to the score in the Eigenvector indicator

there are other valuable tourist-recreational elements. To test this, we turn to content analysis below.

Tag networks show clearly differentiated structures. As can be seen in Fig. 2, Cabrera has a highly centralized graph around the word "island", while in the case of the Cíes the graph is organized around six categories with high degree centrality (i.e., "sea", "beach", "sky", "landscape," "blue," and "water"). Second, regarding the Betweenness indicator, in Cabrera the word "island" stands out again, while in the Atlantic archipelago it is the word "beach" that acts as a bridge with the rest of the descriptors. This could be the axis that structures the perception of the visitors in each natural space, respectively, visiting an island, as opposed to going to the beach. 

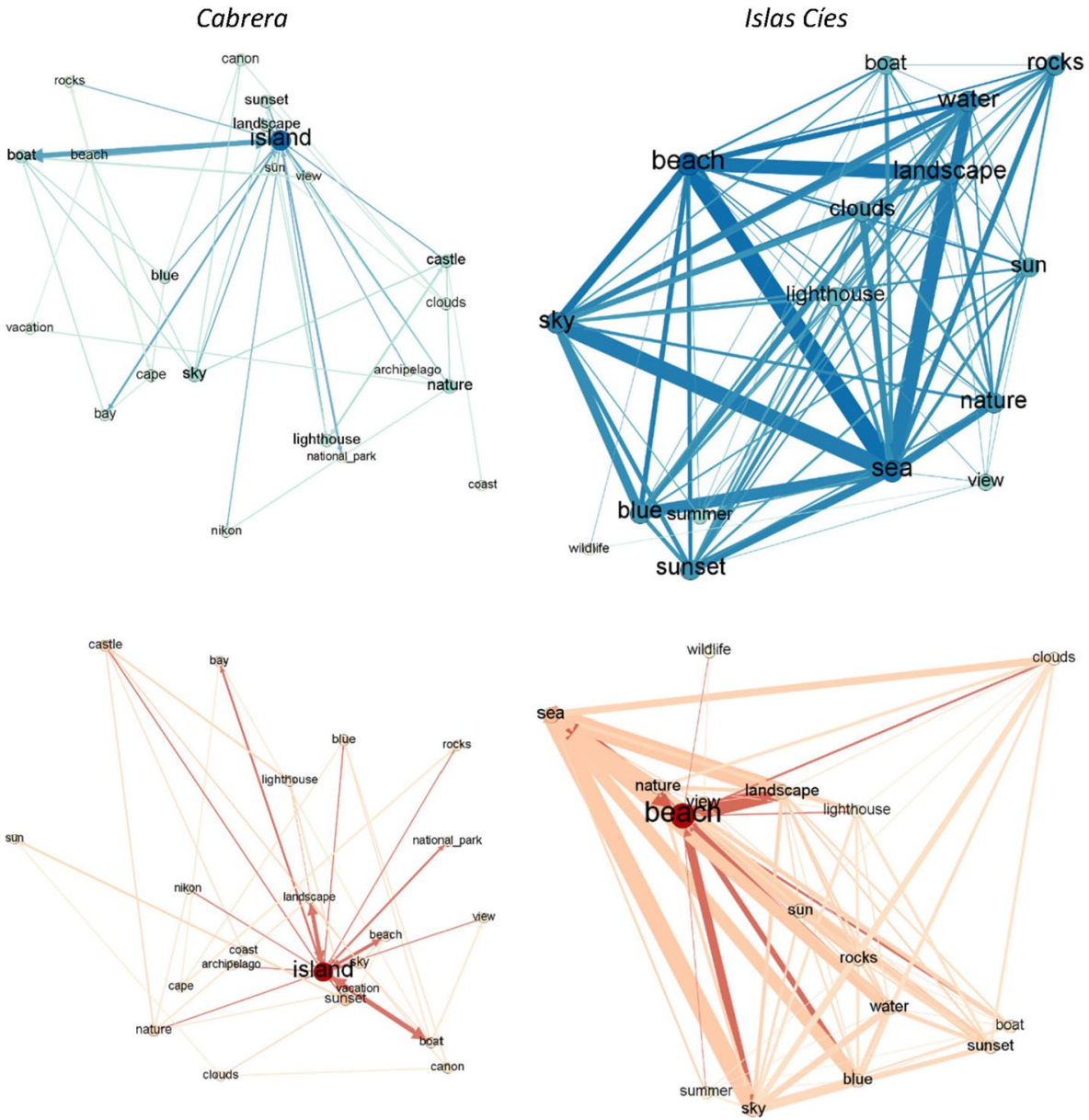

Fig. 2 Tag networks using Degree and Betweenness measures. Each graph represents the co-occurrences between tags after eliminating the terms referring to geographic location. The size of each edge corresponds to the frequency of photographs in which both tags coincide. The size of each word reflects the Degree (blue) or Betweenness (orange) ranking. The networks are represented with Gephi (Bastian et al., 2009), using the ForceAtlas2 layout algorithm (Jacomy et al., 2014). In the graphs in blue Degree is used as the repulsion force, and in orange Betweenness

\subsection{Validation by observers}

Through content analysis, we find that most of the photographs are a representation of the landscape $(\mathrm{n}=92,76.7 \%)$ and its aesthetic or natural values. Second, although much less frequently, the biodiversity of the environment is represented $(n=16,13.3 \%)$. There are also cases of photographic posing $(n=11,9.2 \%)$ and other forms of representation of human activity $(n=7,5.8 \%)$. Table 4 shows the complete data.

The comparison of the descriptive categories allows us to identify some differences between the two archipelagos analyzed. On the Cíes Islands, images of flora and fauna 
Table 4 Descriptive categories of photos

Table 5 Photographic motifs

\begin{tabular}{|c|c|c|c|c|c|c|}
\hline & \multicolumn{2}{|c|}{$\begin{array}{l}\text { Cabrera Island } \\
(n=60)\end{array}$} & \multicolumn{2}{|c|}{$\begin{array}{l}\text { Cíes Islands } \\
(n=60)\end{array}$} & \multicolumn{2}{|c|}{$\begin{array}{l}\text { Total } \\
(n=120)\end{array}$} \\
\hline & $N$ & $\%$ & $N$ & $\%$ & $N$ & $\%$ \\
\hline Landscape & 47 & 78.33 & 45 & 75 & 92 & 76.7 \\
\hline Biodiversity & 4 & 6.66 & 12 & 20 & 16 & 13.3 \\
\hline Posing & 1 & 1.66 & 10 & 16.66 & 11 & 9.2 \\
\hline Human activity & 5 & 8.33 & 2 & 3.33 & 7 & 5.8 \\
\hline Accommodation & 6 & 1 & 1 & 1.66 & 7 & 5.8 \\
\hline Food & - & - & - & - & - & - \\
\hline
\end{tabular}

The categories are based on Hausmann et al. (2018). Each image can belong to more than one category simultaneously

\begin{tabular}{|c|c|c|c|c|c|c|}
\hline & \multicolumn{2}{|c|}{$\begin{array}{l}\text { Cabrera } \\
\text { Island } \\
(n=60)\end{array}$} & \multicolumn{2}{|c|}{$\begin{array}{l}\text { Cíes Islands } \\
(n=60)\end{array}$} & \multicolumn{2}{|c|}{$\begin{array}{l}\text { Total } \\
(n=120)\end{array}$} \\
\hline & $N$ & $\%$ & $N$ & $\%$ & $N$ & $\%$ \\
\hline Sea and rocks & 33 & 55 & 34 & 56.66 & 67 & 55.8 \\
\hline Lighthouse and/or castle & 23 & 38.33 & 4 & 6.66 & 27 & 22.5 \\
\hline Ships & 18 & 30 & 6 & 10 & 24 & 20 \\
\hline Sunset & 7 & 11.66 & 6 & 10 & 13 & 10.8 \\
\hline Animals & 1 & 1.66 & 6 & 10 & 7 & 5.8 \\
\hline People on the beach & 1 & 1.66 & 5 & 8.33 & 6 & 5 \\
\hline
\end{tabular}

Own elaboration. Each image can belong to more than one category simultaneously
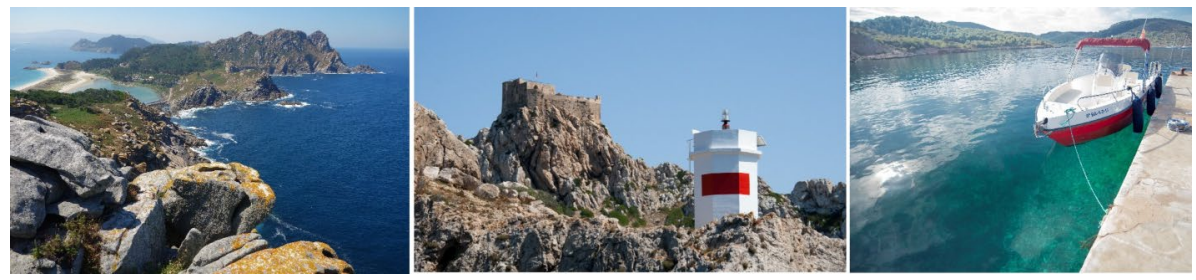

Fig. 3 Illustration of the most common photographic motifs. The three most common photographic motifs are sea and cliff landscapes, images of the lighthouse or castle, and boats. From the left to the right, photos show: Cíes Islands from Alto del Príncipe, of Jorge Tomé Hernando (CC BY 2.0), https://www.flickr. com/photos/jtome/28641496966/. Lighthouse and Cabrera castle, by Iñaki Pérez de Albéniz (CC BY 2.0), https://www.flickr.com/photos/atreyusan/4910476131/. Boat on the Island of Cabrera, by Calvin Smith (CC BY 2.0), https://www.flickr.com/photos/calvinsmith/15021916260/

and photographic posing are more frequent, while on Cabrera Island other forms of human activity are more common.

Table 5 summarizes the most common photographic motifs. The predominant subject of the photographs is the sea and rock landscapes $(n=67,55.8 \%)$. Second, images of historic buildings $(n=27,22.5 \%)$ and boats $(n=24,20 \%)$. These last two categories are clearly 
Table 6 Evaluation of cultural marine ecosystem services

\begin{tabular}{|c|c|c|c|c|c|c|c|}
\hline & \multicolumn{2}{|c|}{$\begin{array}{l}\text { Cabrera Island } \\
(n=60)\end{array}$} & \multicolumn{2}{|c|}{$\begin{array}{l}\text { Cíes Islands } \\
(n=60)\end{array}$} & \multicolumn{2}{|c|}{ Total $(n=120)$} & \multirow[t]{2}{*}{$\mathrm{ICC}$} \\
\hline & $M$ & DT & $M$ & DT & $M$ & DT & \\
\hline Artistic or cultural expression & 1.09 & 0.502 & 1 & 0 & 1.05 & 0.357 & - \\
\hline Living cultural heritage & 1 & 0 & 1 & 0 & 1 & 0 & - \\
\hline Gastronomy & 1 & 0 & 1 & 0 & 1 & 0 & - \\
\hline Historical monuments & 2.36 & 1.694 & 1.40 & 1.77 & 1.88 & 1.533 & 0.866 \\
\hline Landscape appreciation & 3.77 & 1.623 & 3.74 & 1.668 & 3.75 & 1.642 & 0.873 \\
\hline Fauna or flora & 1.29 & 1.016 & 1.82 & 1.561 & 1.55 & 1.340 & 0.958 \\
\hline Natural monuments & 1.32 & 0.926 & 1.16 & 0.648 & 1.24 & 0.801 & 0.331 \\
\hline Religious activities/rituals & 1.08 & 0.521 & 1.02 & 0.183 & 1.05 & 0.391 & - \\
\hline Research and education & 1 & 0 & 1 & 0 & 1 & 0 & - \\
\hline Social recreation & 1.46 & 1.092 & 1.61 & 1.368 & 1.53 & 1.237 & 0.483 \\
\hline Recreational activities & 1.68 & 1.372 & 1.30 & 1.017 & 1.49 & 1.220 & 0.159 \\
\hline Other & 1.34 & 1.114 & 1.06 & 0.373 & 1.20 & 0.840 & 0.683 \\
\hline
\end{tabular}

Bold values indicate the categories that are statistically significant

The categories are based on Ruiz-Frau et al. (2020), with some adaptations to the original classification of Retka et al. (2019). The intraclass correlation index (ICC) calculates the consistency between observers with a mixed model of two factors

more frequent in the case of the Balearic archipelago, where both the n'Ensiola lighthouse and the Cabrera castle and recreational boats are recurring motifs. Both the local fauna and the images of people on the beach are comparatively more frequent in the Galician archipelago. Figure 3 illustrates the three most prominent photographic motifs.

Table 6 summarizes the valuation of cultural ecosystem services, carried out by the two independent observers. The three most common elements are the appreciation of the landscape, the observation of historical monuments and the sighting of flora or fauna. These three themes coincide with those that show greater consistency among observers, with intraclass correlation indicators above 0.866 .

The appreciation of the landscape is, by far, the predominant function in the photographic representation of the two analyzed National Parks. ${ }^{3}$ Several locations are repeated in the analyzed sample. In Cabrera, many photographs show the landscape from the port, while in the Cíes Islands, views from the peninsular coast or from Alto del Príncipe, on Monte Agudo, are very frequent. The theme of the photos corresponds to the type of visits organized on each island. In the case of Cabrera, the visits are restricted to a defined geographical area, which includes the port, the castle, and the lighthouse. On the boat trip, visitors circumnavigate the island, without touching land at any other point. In the Cíes Islands, visitors can spend the day on a long sandy beach (while in Cabrera there is only a small beach in the port, where tourists bathe).

There are also some differences between the two study areas. Both historical monuments $(t=5089, p<0.0001)$, and recreational activities $(t=2459, p<0.015)$ are more present in Cabrera than in the Cíes Islands. In both cases, photographic shots seem to be in

${ }^{3}$ In the content analysis this function is even more evident than in the tags assigned by users. 


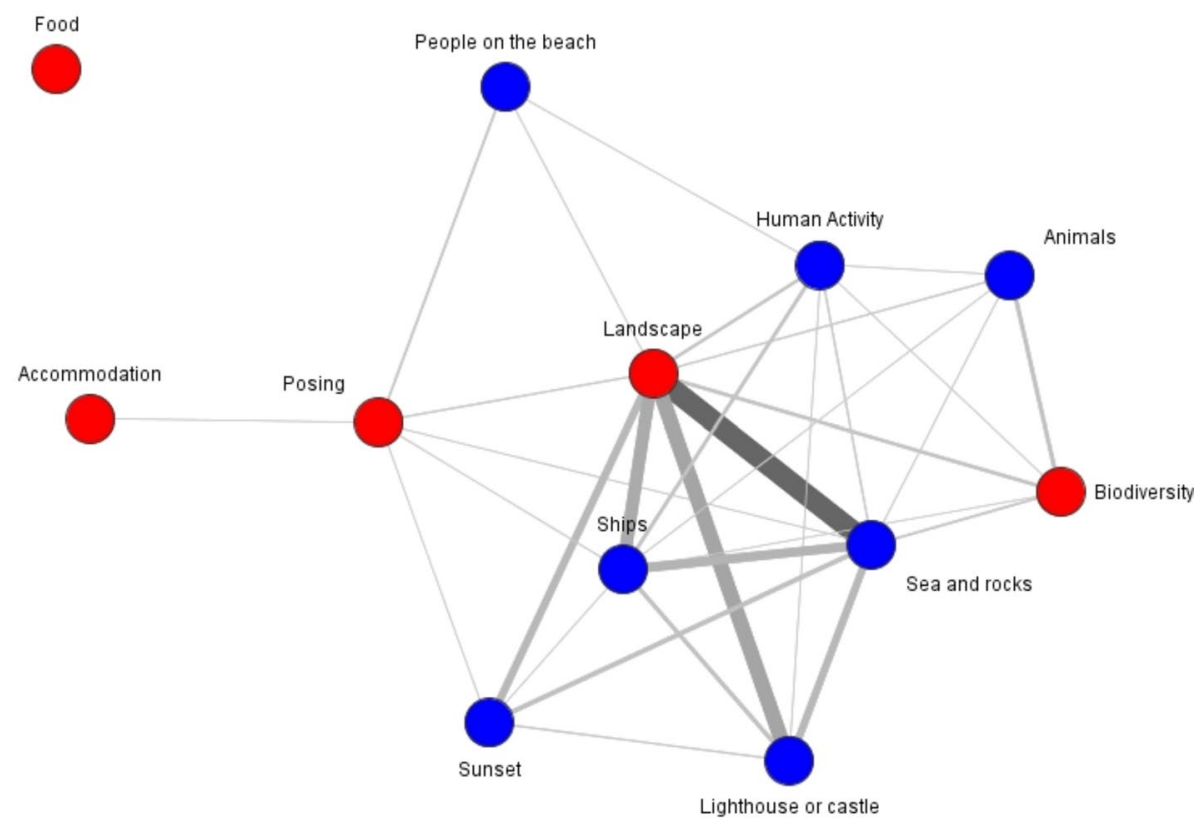

Fig. 4. Two-mode network with descriptive categories and photographic motifs. The valued network of affiliation between descriptive categories (in red) and photographic motifs (in blue), represented with Visone 2.18 (Brandes \& Wagner, 2004). The thickness of the edge indicates the frequency in the match matrix

part determined by tourist activities. In Cabrera the activity revolves around recreational boats and snorkeling in crystal clear waters, while in the Cíes Islands, photos are taken on the beach, on the way to the lighthouse and on the boat trip from the coast of the peninsula. In the Cíes Islands the representation of fauna or flora is also more common $(t=-3.088$, $p<0.002)$. Among other species, the photos show lizards, rabbits, seagulls, shearwaters, and other seabirds.

Five ecosystem services were practically not observed in the sample of photographs analyzed: cultural expression, living heritage, religious activities, gastronomy, and educational or research activities.

Taken together, the three classifications used for content analysis offer a fairly similar result when comparing the two archipelagos. We confirm this through the analysis of the affiliation network between the descriptive categories and the photographic motifs, represented in Fig. $4 .{ }^{4}$ The landscape articulates the core of the network and tends to coincide, from highest to lowest, with views of the sea and rocks, the captures of the lighthouse or the castle, recreational boats, and sunsets. Finally, the scenes of persons posing for the photo usually occur in tourist hospitality environments and often represent people on the beach.

\footnotetext{
${ }^{4}$ The organization of the category system is confirmed with the dendrogram resulting from the hierarchical cluster analysis (see Annex 1). The tags are grouped into categories related to landscape appreciation, biodiversity appreciation, and tourist uses.
} 


\section{Discussion}

The analysis of photographs shared on social media allows us to assess the characteristics of the landscape and the cultural ecosystem services obtained from Marine Protected Areas. In the case of Cabrera and the Cíes Islands the appreciation of the landscape by visitors clearly predominates, complemented to a lesser extent by the historical attractions of the built environment and the sighting of seabirds. The landscape was also the predominant dimension in a study on the largest marine protected area in Brazil (Retka et al., 2019).

Second, systematic observation of the photographs allows comparison between the different protected areas. In our case, we found that infrastructures, historic buildings, and boats used for amusement have more relative weight in Cabrera, while fauna and beach tourism have more relative weight in the Cíes Islands. This result shows the existence of a geographical area in which cultural-recreational uses predominate (i.e., Cabrera), compared to another with a certain bias toward social activities in the natural environment (Cíes Islands). Previous comparative studies with photo content analysis have differentiated the recreational functions of mountainous areas and bodies of water, compared to the sociocultural values of grasslands and urban infrastructures (Oteros-Rozas et al., 2018).

However, throughout this study we found some important limitations in the descriptive use of the photographs. On the one hand, some of the ecosystem services remain off the radar, either because they are less frequent, because they are less suitable for visual representation (e.g., spiritual values) or because of reliability problems when identifying them. These last two issues could be partially overcome with the analysis of tags associated with the photos (e.g., Ruiz-Frau et al., 2020). However, user-generated tags are not systematic and sometimes highlight superficial or secondary aspects of each image. The present study shows that manual analysis of photographs in conjunction with content analysis by outside observers provided a more nuanced examination of the natural environment than analysis of data pulled directly from social media. Previous studies have shown that machine learning tools are not always effective in evaluating ecosystem services (Ruiz-Frau et al., 2020). There may also be biases in the representativeness of both the number and characteristics of visitors (Retka et al., 2019), as well as the type of activity they carry out in natural areas (Hausmann et al., 2018). Likewise, the validity of the geolocation provided by users has also been questioned (Oteros-Rozas et al., 2018).

Accordingly, future research should focus in the short term on comparative examination of diverse platforms in different geographical areas (along the lines started for example by de Ruiz-Frau et al., 2020). In our study, we focus on a digital platform that is widely used by photographers and other users interested in the world of photography. It is likely that the presence of landscape values is more common on Flickr than on other websites more oriented to sharing personal content. In the exploratory phase, we also found that in the Galapagos Islands the representation of animal life was enormously more frequent than in the two case studies that we finally selected. Our description of ecosystem services is quite similar to that obtained by other authors, also with Flickr (Hausmann et al., 2018; OterosRozas, et al., 2018; Retka et al., 2019). ${ }^{5}$

It should also be considered that a small number of users are usually responsible for a high percentage of the photographs. Consequently, it can be useful to incorporate strategies to analyze individual profiles and create aggregated typologies of users. The extraction

${ }^{5}$ Compared to Instagram and Panoramio. 
of digital data is not based on obtaining representative samples of the population but on the exhaustive collection of photographs and tags. Indeed, the number of photos associated with a geographical location is one of the most used indicators in the evaluation and management of ecosystems (Zhang et al., 2020). The analysis of social networks also does not follow the logic of sampling in the collection, analysis, and interpretation of data. However, it is necessary to prevent possible biases when the representation of the landscape is based on the perception of a small number of users.

Among other practical implications, the digital content generated by the user makes it possible to identify the most visited places, discover places of tourist interest or evaluate human pressures to which protected natural areas are subjected. In the two archipelagos analyzed, tourist visits follow a defined pattern that depends both on the activity carried out (for example, traveling by boat to the island or going up the path that leads to the lighthouse) and on the distinctive characteristics of the environment (for example, having a castle or a beach area for bathing). This information could be used in the design of tourist itineraries, marine spatial planning, and coastal development. It can also serve to assess environmental risks or as an indicator of potential human impacts. That is why its use has been recommended as a complementary tool in the management of protected areas (Retka et al., 2019), and in the evaluation of the preferences of tourists who visit the area (Hausmann et al., 2018). In urban contexts it has also been applied to describe the mobility patterns of the population (Manca et al., 2017).

The photos shared on social media make it possible to evaluate the substitution of ecosystem services related to fishing for tourist uses of marine protected areas. Indeed, tourism has frequently relegated fishing to a secondary place in coastal communities, even though in many cases both can function as complementary activities (Maya-Jariego et al., 2017). However, tourism also largely determines consumer preferences for certain highly local valued species and, consequently, affects the opportunities of the different actors involved in the commercialization of seafood (García-Rodrigues \& Villasante, 2016). Accordingly, it has been recommended to regulate the number of tourists visiting marine protected areas (Lopes et al., 2017). The evaluation through photographs of the ecosystem services related to gastronomy could be useful to monitor this activity.

\subsection{Natural values and subjective assessment of the landscape}

National parks normally have special biological or landscape characteristics, around which tourist uses are promoted. The two archipelagos analyzed stand out, among other natural values, for the richness of their seabed, the uniqueness of the coastal landscape, and the diversity of seabirds.

However, as we have shown, this biodiversity is poorly represented in the photographs that users share on the internet. For example, the underwater landscape in the Cíes Islands has an enormous biodiversity of marine algae, fish, and echinoderms. However, the most tourists only pay a one-day visit to Rodas beach and have little knowledge of the value of the marine ecosystems in the area. That is why snorkeling has been suggested as an activity that facilitates environmental education and that has lower ecological impacts than boat trips (Piñeiro-Corbeira et al., 2020). In fact, it has been proven that tourist boats remove certain species of birds, such as shaggy cormorants (Phalacrocorax aristotelis), from the best feeding areas (Velando \& Munilla, 2011).

With regard to the Balearic archipelago, seagrass beds (Posidonia oceanica) form a highly productive coastal ecosystem (Leiva-Dueñas et al., 2020). However, the 
representation of the landscape by visitors to the Island of Cabrera is also far from the most representative ecological values of the National Park. Ultimately, the recreational activity carried out by users directly influences the representation of the landscape, so the redesign of scheduled tourist visits has enormous potential to promote intergenerational knowledge of the local environment and develop environmental education programs. Yet, we normally face a dilemma between restricting access to visitors, for preservation purposes, or scheduling tourist activities in areas of high ecological value (such as the well-preserved Posidonia beds in Cabrera).

Ultimately, the subjective representation of the natural environment not only depends on the characteristics of the landscape or the cultural meanings associated with it, but direct interaction, whether personal or in a group, transforms the cognitive map and influences in the consequent aesthetic appreciation (Zube et al., 1982). Accordingly, the meticulous planning of the tourist experience is one of the strategies that can contribute to a better knowledge and appreciation of marine protected areas. It is also possible to think that photos facilitate a vicarious experience of the landscape and, consequently, indirectly contribute to disseminating the natural values associated with the local environment. This finding coincides with the importance attributed to the social context in the evaluation of ecosystem services (Felipe-Lucia et al., 2015; Vihervaara et al., 2010).

Social media data, particularly photographs, provide a proxy indicator of subjective assessment of the landscape. Compared to other information gathering methods and techniques, such as interviews or surveys, they are based on user behavior and, as such, are less exposed to the biases of social desirability. The most photographed places usually show the preferences of the visitors, and more specifically, the density of geolocated content correlates with the number of visits (Zhang et al., 2020). In our study, we have observed that the centralization of the tag network is inversely related to the diversity of ecosystem uses associated with the environment. The words with higher Betweenness reflect the axes around which the perception of tourists visiting the area is organized. Hence, the greatest potential of social media data lies precisely in the indirect assessment of landscape characteristics and marine ecosystem services.

The comparative study of Cabrera and Cíes archipelagos revealed that the photographs shared on Flickr do not reflect all the ecological and cultural richness of their ecosystems. On the one hand, there are limitations attributable in part to the subjective process of capturing and sharing images. For example, the underwater landscape requires a type of special cameras and is associated with diving or snorkeling practices that are less widespread among tourists than visits by boat. Similarly, more intangible values, such as artistic or religious experience, can be more difficult to represent or interpret. On the other hand, there are limitations derived from accessibility to natural spaces and the design of permitted tourist activities. Thus, in the case of Cabrera, visitors mainly access the urbanized area, around the port, and present fewer opportunities to see colonies of birds or the great abundance of reptiles. However, despite these limitations, the photographs shared in the media provide valuable information which can be used in the control, surveillance, and management of marine protected areas, as well as to convey the value of natural settings. In this case study, we found that both landscape and historical buildings have an emblematic value, which works as an effective tourist attraction for visitors. Fauna also constitutes one of the outstanding natural resources in the perception of users and potentially can function as an element of tourist motivation from which to access other valuable elements of the natural environment. 


\section{Conclusion}

The photographs uploaded by users to an image hosting service on the internet show that the appreciation of the landscape is the predominant ecosystem service in their visits to two natural protected areas in Spain. First, photos are especially helpful in describing the features of the landscape. Complementarily, they also report on the natural values and some of the tourist-recreational uses prevalent in the environment. For their part, tag networks offer an efficient approach to the cognitive representation of the natural environment. However, despite the promising nature of the automated analysis of ecosystem services, user-generated digital content still requires an elaborate investigation and a further data processing procedure. The analysis of the content shared on social media is a useful tool for the evaluation of marine ecosystems when it is based on the careful selection of photographs, disambiguation of tags, selective analysis of the most relevant relationships, and validation with qualitative observational strategies. Tourism management can provide the type of experiences that transform the perception of the environment, enhancing the natural values of protected areas.

\section{Appendix}

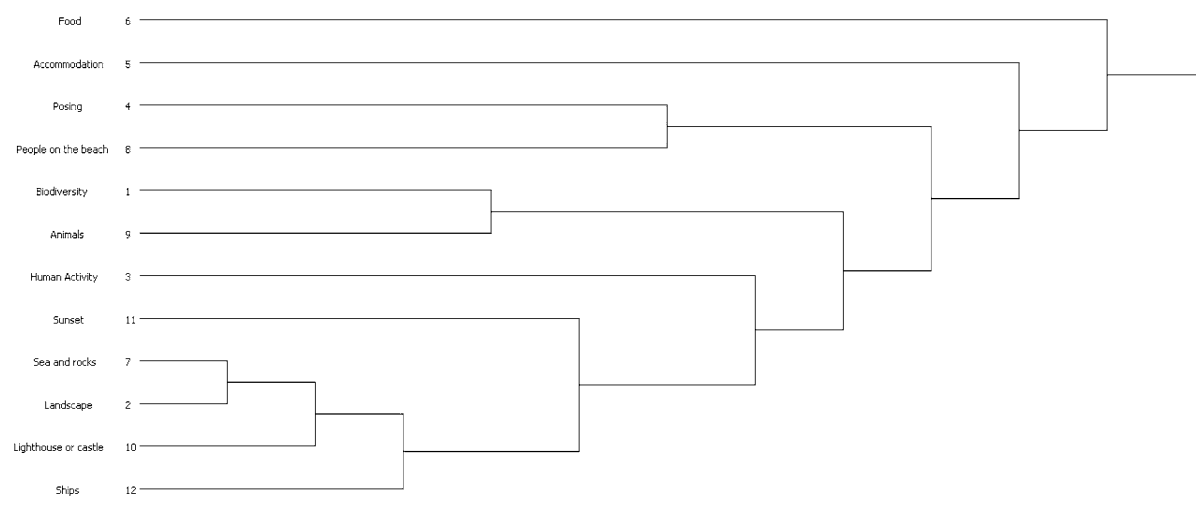

Annex 1 Dendrogram of the categories used in the content analysis

Funding Open Access funding provided thanks to the CRUE-CSIC agreement with Springer Nature.

Open Access This article is licensed under a Creative Commons Attribution 4.0 International License, which permits use, sharing, adaptation, distribution and reproduction in any medium or format, as long as you give appropriate credit to the original author(s) and the source, provide a link to the Creative Commons licence, and indicate if changes were made. The images or other third party material in this article are included in the article's Creative Commons licence, unless indicated otherwise in a credit line to the material. If material is not included in the article's Creative Commons licence and your intended use is not permitted by statutory regulation or exceeds the permitted use, you will need to obtain permission directly from the copyright holder. To view a copy of this licence, visit http://creativecommons.org/licenses/by/4.0/. 


\section{References}

Altman, N., Carley, K. M., \& Reminga, J. (2017). Ora user's guide 2017. Carnegie-Mellon University, Pittsburgh PA Institute of Software Research International, Technical Reports, 3, 2.

Ban, N. C., Davies, T. E., Aguilera, S. E., Brooks, C., Cox, M., Epstein, G., Evans, L. S., Maxwell, S. M., \& Nenadovic, M. (2017). Social and ecological effectiveness of large marine protected areas. Global Environmental Change, 43, 82-91.

Bastian, M., Heymann, S., \& Jacomy, M. (2009, March). Gephi: An open source software for exploring and manipulating networks. In Proceedings of the international AAAI conference on web and social media (Vol. 3, No. 1).

Brandes, U., \& Wagner, D. (2004). Analysis and visualization of social networks. In M. Jünger \& P. Mutzel (Eds.), Graph drawing software (pp. 321-340). Springer.

Cambiè, G., Ouréns, R., Vidal, D. F., Carabel, S., \& Freire, J. (2012). Economic performance of coastal fisheries in Galicia (NW Spain): Case study of the Cíes Islands. Aquatic Living Resources, 25(2), 195-204.

Carley, K. M., Columbus, D., \& Azoulay, A. (2012). Automap user's guide 2012. Carnegie-Mellon University.

de Juan, S., Ospina-Álvarez, A., Villasante, S., \& Ruiz-Frau, A. (2021). A graph theory approach to assess nature's contribution to people at a global scale. Scientific Reports, 11, 9118. https://doi.org/ $10.1038 / \mathrm{s} 41598-021-88745-\mathrm{z}$

Di Franco, A., Thiriet, P., Di Carlo, G., Dimitriadis, C., Francour, P., Gutiérrez, N. L., de Grissac, A. J., Koutsoubas, D., Milazzo, M., del Mar Otero, M., \& Piante, C. (2016). Five key attributes can increase marine protected areas performance for small-scale fisheries management. Scientific Reports, 6(1), 1-9.

Edgar, G. J., Stuart-Smith, R. D., Willis, T. J., Kininmonth, S., Baker, S. C., Banks, S., Barrett, N. S., Becerro, M. A., Bernard, A. T., Berkhout, J., \& Buxton, C. D. (2014). Global conservation outcomes depend on marine protected areas with five key features. Nature, 506(7487), 216-220.

Felipe-Lucia, M. R., Comín, F. A., \& Escalera-Reyes, J. (2015). A framework for the social valuation of ecosystem services. Ambio, 44(4), 308-318.

Fonseca, C., Silva, C. P. D., Calado, H., Moniz, F., Bragagnolo, C., Gil, A., Phillips, M., Pereira, M., \& Moreira, M. (2014). Coastal and marine protected areas as key elements for tourism in small islands. Journal of Coastal Research, 70, 461-466.

García-Rodrigues, J. G., \& Villasante, S. (2016). Disentangling seafood value chains: Tourism and the local market driving small-scale fisheries. Marine Policy, 74, 33-42.

Hausmann, A., Toivonen, T., Slotow, R., Tenkanen, H., Moilanen, A., Heikinheimo, V., \& Di Minin, E. (2018). Social media data can be used to understand tourists' preferences for nature-based experiences in protected areas. Conservation Letters, 11(1), e12343.

Hogg, O. T., Huvenne, V. A., Griffiths, H. J., \& Linse, K. (2018). On the ecological relevance of landscape mapping and its application in the spatial planning of very large marine protected areas. Science of the Total Environment, 626, 384-398.

IBM Corp. (Released 2019). IBM SPSS statistics for windows, version 26.0. IBM Corp.

Jacomy, M., Venturini, T., Heymann, S., \& Bastian, M. (2014). ForceAtlas2, a continuous graph layout algorithm for handy network visualization designed for the Gephi software. PLoS ONE, 9(6), e98679.

Jentoft, S., van Son, T. C., \& Bjørkan, M. (2007). Marine protected areas: A governance system analysis. Human Ecology, 35(5), 611-622.

Leenhardt, P., Low, N., Pascal, N., Micheli, F., \& Claudet, J. (2015). The role of marine protected areas in providing ecosystem services. In Aquatic functional biodiversity (pp. 211-239). Academic Press.

Leiva-Dueñas, C., Leavitt, P. R., Buchaca, T., Cortizas, A. M., López-Merino, L., Serrano, O., Lavery, P. S., Schouten, S., \& Mateo, M. A. (2020). Factors regulating primary producers' assemblages in Posidonia oceanica (L.) Delile ecosystems over the past 1800 years. Science of the Total Environment, 718,137163 .

Lopes, P. F. M., Mendes, L., Fonseca, V., \& Villasante, S. (2017). Tourism as a driver of conflicts and changes in fisheries value chains in Marine Protected Areas. Journal of Environmental Management, 200, 123-134.

Manca, M., Boratto, L., Roman, V. M., i Gallissà, O. M., \& Kaltenbrunner, A. (2017). Using social media to characterize urban mobility patterns: State-of-the-art survey and case-study. Online Social Networks and Media, 1, 56-69. 
Maya-Jariego, I., Holgado, D., \& Florido, D. (2016). Relations between professional groups in the Atlantic and Mediterranean fishing enclaves of Andalusia (Spain): A personal networks approach with clustered graphs. Marine Policy, 72, 48-58.

Maya-Jariego, I., Querevalú-Miñán, J. F., Varela, L. G., \& Ávila, J. (2017). Escape the lion cage: Social networks by catch zones of small-scale fisheries in the oil settlement of Lobitos (Peru). Marine Policy, 81, 340-349.

Oteros-Rozas, E., Martín-López, B., Fagerholm, N., Bieling, C., \& Plieninger, T. (2018). Using social media photos to explore the relation between cultural ecosystem services and landscape features across five European sites. Ecological Indicators, 94, 74-86.

Petrosillo, I., Zurlini, G., Corliano, M. E., Zaccarelli, N., \& Dadamo, M. (2007). Tourist perception of recreational environment and management in a marine protected area. Landscape and Urban Planning, 79(1), 29-37.

Piñeiro-Corbeira, C., Barreiro, R., Olmedo, M., \& De la Cruz-Modino, R. (2020). Recreational snorkeling activities to enhance seascape enjoyment and environmental education in the Islas Atlánticas de Galicia National Park (Spain). Journal of Environmental Management, 272, 111065.

Retka, J., Jepson, P., Ladle, R. J., Malhado, A. C., Vieira, F. A., Normande, I. C., Souza, C. N., Bragagnolo, C., \& Correia, R. A. (2019). Assessing cultural ecosystem services of a large marine protected area through social media photographs. Ocean \& Coastal Management, 176, 40-48.

Ruiz-Frau, A., Ospina-Alvarez, A., Villasante, S., Pita, P., Maya-Jariego, I., \& de Juan, S. (2020). Using graph theory and social media data to assess cultural ecosystem services in coastal areas: Method development and application. Ecosystem Services, 45, 101176.

Sciberras, M., Jenkins, S. R., Mant, R., Kaiser, M. J., Hawkins, S. J., \& Pullin, A. S. (2015). Evaluating the relative conservation value of fully and partially protected marine areas. Fish and Fisheries, 16(1), $58-77$.

Toivonen, T., Heikinheimo, V., Fink, C., Hausmann, A., Hiippala, T., Järv, O., Tenkanen, H., \& Di Minin, E. (2019). Social media data for conservation science: A methodological overview. Biological Conservation, 233, 298-315.

Velando, A., \& Munilla, I. (2011). Disturbance to a foraging seabird by sea-based tourism: Implications for reserve management in marine protected areas. Biological Conservation, 144(3), 1167-1174.

Vihervaara, P., Rönkä, M., \& Walls, M. (2010). Trends in ecosystem service research: Early steps and current drivers. Ambio, 39(4), 314-324.

Willis, C. (2015). The contribution of cultural ecosystem services to understanding the tourism-nature-wellbeing nexus. Journal of Outdoor Recreation and Tourism, 10, 38-43.

Wood, S. A., Guerry, A. D., Silver, J. M., \& Lacayo, M. (2013). Using social media to quantify nature-based tourism and recreation. Scientific Reports, 3(1), 1-7.

Zhang, H., Huang, R., Zhang, Y., \& Buhalis, D. (2020). Cultural ecosystem services evaluation using geolocated social media data: A review. Tourism Geographies. https://doi.org/10.1080/14616688.2020. 1801828.

Zube, E. H., Sell, J. L., \& Taylor, J. G. (1982). Landscape perception: Research, application and theory. Landscape Planning, 9(1), 1-33.

Publisher's Note Springer Nature remains neutral with regard to jurisdictional claims in published maps and institutional affiliations. 